\title{
Casca de soja em substituição ao feno de alfafa em dietas fareladas para coelhos em crescimento
}

\author{
Soybean hulls in the replacemennt of alfafa hay in diet non pelleted for growing rabbits
}

\author{
Geni Salete Pinto de Toledo ${ }^{*}$ Daniel Prois Eggersi ${ }^{\mathrm{II}}$ Leila Picolli da Silva ${ }^{\mathrm{I}}$ Paulo Santana Pacheco ${ }^{\mathrm{I}}$ \\ Ana Carolina Kohlrausch Klinger ${ }^{\mathrm{II}}$ Janaína Roberta Capitânio ${ }^{\mathrm{II}}$ Tiago Schmidt $^{\mathrm{II}}$ Jossiane Ortiz $^{\mathrm{II}}$
}

\section{RESUMO}

$O$ presente trabalho foi realizado no período de 16 de novembro a 28 de dezembro de 2009, totalizando 42 dias. Foram utilizados 36 animais distribuídos em três tratamentos de 12 repetições cada, em delineamento inteiramente casualizado. Os tratamentos consistiram de TA = dieta sem inclusão de casca de soja (CS); TACS=dieta com inclusão de $50 \%$ de casca de soja e TCS=dieta com inclusão de $100 \%$ de casca de soja em substituição ao feno de alfafa. As dietas foram isonutritivas, formuladas para atender às necessidades da categoria correspondente, de acordo com o AEC (1987). Foram avaliados os dados de desempenho animal, as características de carcaça e a viabilidade econômica. Os resultados foram submetidos à analise de variância e as médias comparadas pelo teste de Tukey a 5\% de significância, com auxílio do pacote estatístico SAS (2003). Houve diferença para o consumo alimentar e conversão alimentar, já que os animais alimentados com TCS consumiram menos ração que os do TA e apresentaram melhor conversão. Para as características de carcaça, não houve diferença entre os tratamentos, com exceção do peso de pele, que foi superior para os animais alimentados com a dieta TA. $O$ índice de eficiência econômica demonstrou que a casca de soja pode substituir em $100 \%$ o feno de alfafa.

Palavras-chave: carcaça, co-produtos, desempenho, viabilidade econômica.

\section{ABSTRACT}

The experiment was conducted from November 16 to December 28, 2009, add up 42 days. 36 animals of 35 days old were utilized and assigned to three treatments of 12 repetitions each in experimental design completely randomized. The treatments were: TA=Soybean hulls without; TACS=inclusion soybean hulls $50 \%$ and TCS=inclusion soybean hulls $100 \%$ substitution of Alfalfa at diet. The diets were isonutritives, formulated by requirement AEC (1987). The avaluated parameters were: performance animal, characteristics carcass and analyze economical. Data were analized by analysis of variance and the average compared by Tukey test $(P<0.05)$. Values differences were detected for average feed intake and feed conversion ratio, where rabbits to feeding diets with TCS had consumption lower that to TA and showed better conversion. For the carcass characteristics effects of inclusion of soybean hulls were no significant, with exception of weight epidermis had higger for animals fed with diet TA. The economical analysis of the results showed that the formulation with soybean hulls will be to substitute the alfafa until $100 \%$.

Key words: agricultural by-products, carcass, economical analysis, performance.

\section{INTRODUÇÃO}

A agropecuária mundial tem passado por grandes transformações nos últimos anos, essencialmente motivadas pela produção intensiva de alimentos em espaços reduzidos e com qualidade nutricional que garanta a promoção de saúde ao mercado consumidor. Nesse cenário, a produção de coelhos merece destaque, pois é uma espécie que tem a capacidade de aproveitar os alimentos relativamente ricos em fibras, competindo em menor grau com o homem do que aves e suínos, que consomem maior quantidade de grãos nas suas respectivas dietas. Além

IDepartamento de Zootecnia, Universidade Federal de Santa Maria (UFSM), Av. Roraima, 1000, 97105-900, Santa Maria, RS, Brasil. E-mail: genistoledo@ hotmail.com. *Autor para correspondência.

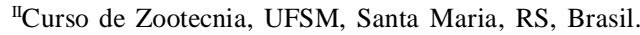


disso, as suas características biológicas (rapidez do ciclo de produção, prolificidade, poder de transformação e ótima qualidade da carne) fazem com que possa desempenhar função importante no melhoramento do regime alimentar da população (LEBAS et al., 1986).

Cerca de $70 \%$ do custo de produção na atividade cunícola é representado pela alimentação, na qual o feno de alfafa é tradicionalmente incluído como fonte de fibra e proteína; porém, esse ingrediente pode onerar em até $40 \%$ o custo das dietas (HERRERA, 2003; SCAPINELLO et al., 2003). Devido ao elevado custo, esforços científicos têm sido direcionados para estudar fontes alternativas ao uso do feno de alfafa, que, além de baratear, também proporcione melhorias ou mantenha a mesma eficiência de conversão observada com os ingredientes tradicionais (RETOREet al.,2010).

A utilização de co-produtos agroindustriais na alimentação animal sempre foi uma realidade, e a possibilidade de inclusão depende, entre vários fatores, da disponibilidade desse material, dos níveis empregados na produção animal, da competição com outros produtos alternativos, da segurança de utilização, dos custos e, logicamente, do valor nutricional (MEJIA, 1999). Entre eles, destaca-se a casca de soja, que é obtida a partir do beneficiamento para extração do óleo, representando em média $8 \%$ do peso do grão (KOLPFENSTEIN \& OWEN, 1987). Esse co-produto se destaca pela elevada oferta, preços competitivos e composição bromatológica que se adéqua à alimentação cunícola, pois possui proporção de frações altamente fermentáveis (pectinas, hemiceluloses e celulose), associada à baixa presença de ligninas, um dos principais componentes que afeta negativamente a digestão de fibra (SERRANA, 2006).

No caso de coelhos, ingredientes volumosos que apresentam maior concentração de polímeros não amídicos (ex. pectinas, hemiceluloses e celuloses) e com menor teor de lignina, como a casca de soja, podem ser degradados mais intensamente no intestino grosso, quando comparado a volumosos convencionais (ex. feno de alfafa), devido à maior acessibilidade dos constituintes fermentáveis à microbiota cecocólica (NICODEMUS et al., 2007).

Não obstante, em níveis em que a substituição do feno de alfafa pela casca de soja não afeta o desempenho animal, a viabilidade econômica pode ser melhorada devido ao menor custo desse ingrediente, pois ele não chega a $50 \%$ do custo do feno de alfafa. No entanto, as informações quanto ao uso desse ingrediente alternativo para coelhos ainda são escassas, motivando a condução do presente trabalho, que teve por objetivo avaliar os efeitos sobre o desempenho, parâmetros de carcaça e a viabilidade econômica da substituição do feno de alfafa por casca de soja, em rações para coelhos Nova Zelândia Branco em crescimento.

\section{MATERIAL E MÉTODOS}

O experimento foi conduzido no período de 16 de novembro a 28 de dezembro de 2009 , totalizando 42 dias.

Foram utilizados 36 coelhos, 18 machos e 18 fêmeas da raça Nova Zelândia Branca, desmamados aos 35 dias de idade e alojados individualmente em gaiolas de cimento pré-moldado, com $0,7 \times 0,5 \times 0,4 \mathrm{~m}$, piso e frente de arame galvanizado, equipadas com comedouros e bebedouros tipo potes cerâmicos. $\mathrm{O}$ delineamento utilizado foi o inteiramente casualizado com três tratamentos e 12 repetições, sendo cada animal considerado uma unidade experimental.

Os animais foram submetidos aos seguintes tratamentos: $\mathrm{TA}=$ dieta sem inclusão de casca de soja; TACS = substituição de $50 \%$ de alfafa por casca de soja; e TCS = substituição de $100 \%$ de alfafa por casca de soja (Tabela 1). As dietas foram isonutritivas, formuladas para atender às necessidades da categoria correspondente, de acordo com o AEC (1987). As rações foram fareladas e elaboradas na Fábrica de Ração do Departamento de Zootecnia da UFSM. As análises bromatológicas foram realizadas de acordo com AOAC (1995).

A pesagem dos animais e da ração foi realizada aos 35 e aos 77 dias, sempre nos primeiros horários da manhã. No final do período experimental, foi realizado o abate dos animais para obtenção das características de carcaça, retirada da pele e evisceração. A carcaça foi pesada juntamente com os rins e fígado, em balança digital. Os parâmetros avaliados foram o peso vivo (PV), ganho médio diário (GMD), consumo diário de ração (CDR), conversão alimentar (CA), peso de carcaça quente (PCQ), rendimento de carcaça quente (RCQ), peso da pele (PP), peso do trato gastrointestinal (TGI), Estômago cheio (EC), peso de ceco vazio (PCV) e peso de fígado (PF).

No final do experimento, foi feito o índice de eficiência bioalimentar (IEBA), que foi calculado multiplicando-se o custo da dieta pela conversão alimentar, segundo COSTA (1999). Os resultados foram submetidos à análise de variância e, após, compararamse as médias pelo teste de Tukey a 5\% de significância, com auxílio do pacote estatístico SAS (2003).

\section{RESULTADOS E DISCUSSÃO}

Os dados de desempenho (Tabela 2) mostram que os animais alimentados com dieta 
Tabela 1 - Formulação das dietas experimentais (\%).

\begin{tabular}{|c|c|c|c|}
\hline \multirow{2}{*}{ Ingredientes } & \multicolumn{3}{|c|}{-------Tratamentos---------. } \\
\hline & TA & TACS & TCS \\
\hline Milho & 17,25 & 17,6 & 17,6 \\
\hline Casca de arroz & 6,00 & 5,02 & 4,72 \\
\hline Farelo de trigo & 25,0 & 25,0 & 25,0 \\
\hline Feno de alfafa & 30,0 & 15,0 & 0,00 \\
\hline Farelo de soja & 17,5 & 20,9 & 24,3 \\
\hline Óleo de soja & 2,50 & 2,80 & 3,70 \\
\hline Casca do grão de soja & 0,00 & 11,0 & 22,0 \\
\hline Sal & 0,5 & 0,5 & 0,5 \\
\hline Fosfato bicálcico & 0,81 & 1,00 & 1,00 \\
\hline Calcário calcitico & 0,24 & 0,98 & 0,98 \\
\hline Premix vitamínico e Mineral $^{1}$ & 0,2 & 0,2 & 0,2 \\
\hline Total & 100 & 100 & 100 \\
\hline \multicolumn{4}{|c|}{ Composição bromatológica } \\
\hline Proteína bruta $(\%)$ & 18,00 & 18,00 & 18,00 \\
\hline Extrato etéreo (\%) & 3,00 & 3,00 & 3,00 \\
\hline $\operatorname{FDA}(\%)$ & 15,0 & 15,0 & 15,0 \\
\hline Cálcio (\%) & 0,84 & 0,84 & 0,84 \\
\hline Fósforo útil (\%) & 0,45 & 0,45 & 0,45 \\
\hline Fósforo total $(\%)$ & 0,7 & 0,7 & 0,7 \\
\hline Energia digestível (Kcal kg ${ }^{-1}$ ) & 2600 & 2600 & 2600 \\
\hline Lisina total $(\%)$ & 0,70 & 0,70 & 0,70 \\
\hline Sódio $(\%)$ & 0,23 & 0,23 & 0,23 \\
\hline
\end{tabular}

Composição da casca de soja (\%): proteína bruta 10.65; gordura 1.14; FDA 50.36; hemicelulose 20.42; celulose 47.78; lignina 5.26; fibra solúvel 17.09

contendo casca de soja (TCS) consumiram menos ração que os alimentados com feno de alfafa (TA), obtendo melhor conversão, provavelmente pelo melhor aproveitamento digestivo e metabólico das frações fibrosas da casca de soja. Esse fato condiz com a descrição de QUADROS et al. (2007), que citam que a casca de soja, embora seja um alimento fibroso como o farelo de trigo, possui grande quantidade de pectina, que é altamente digestível. A casca de soja, por conter maior proporção de celulose e hemiceluloses em relação à lignina, deve ter proporcionado maior tempo de retenção e disponibilidade de nutrientes, assim como melhor degradação da fração fibrosa pela atividade microbiana cecal, contribuindo para melhor digestibilidade dessa ração. RETORE et al. (2010) também observaram melhores coeficientes de digestibilidade aparente da matéria seca, matéria orgânica e fibra em detergente neutro de rações contendo casca de soja em substituição ao feno de alfafa. Tal fato foi atribuído à menor lignificação e ao maior teor de hemiceluloses dessa fonte, o que proporcionou maior tempo de retenção para atividade fermentativa, aliado ao maior efeito antiperistáltico, contribuindo para melhor colonização e ação enzimática da microflora do ceco-cólon sobre a fração fibrosa.

O peso vivo dos animais aos 77 dias não diferiu entre os ingredientes testados, concordando com ARRUDA et al. (2003), que, ao testarem diferentes fontes de fibra (feno de alfafa e casca de soja), não observaram diferença para peso final. Esse resultado é corroborado por FIGUEIRA (2009), que, ao substituir feno de alfafa e coastcross por casca de soja moída, ensilada com e sem inoculante para coelhos dos 32 aos 70 dias, não verificou diferenças significativas entre os tratamentos e a dieta referência.

O peso de carcaça, rendimento de carcaça e o peso do fígado (Tabela 3) também não apresentaram diferença entre os tratamentos testados. Já o peso de pele foi significativamente superior para os animais que consumiram dieta com feno de alfafa, provavelmente pelo maior teor de gordura hipodérmica observado nesses animais, o que representa fator indesejável ao beneficiamento da pele, considerando que maior teor de gordura leva à necessidade de limpeza durante ocurtimento.

Não houve diferença para pesos do trato gastrintestinal e estômago repletos, bem como, para

Tabela 2 - Médias de peso vivo inicial (PVI), peso vivo final (PVF), consumo diário de ração (CDR), ganho médio diário (GMD) e conversão alimentar (CA) de coelhos dos 35 aos 77 dias de idade.

\begin{tabular}{llll}
\hline Parâmetros & \multicolumn{1}{c}{ TA } & \multicolumn{1}{c}{ TACS } & \multicolumn{1}{c}{ TCS } \\
\hline PVI $(\mathrm{g})$ & $617,0 \pm 60,4$ & $611,5 \pm 85,6$ & $630,5 \pm 89,4$ \\
PVF $(\mathrm{g})$ & $1995,0 \pm 10,1$ & $1963,0 \pm 128,4$ & $1990,0 \pm 55,7$ \\
CDR $(\mathrm{g})$ & $99,4 \mathrm{a} \pm 8,8$ & $91,3 \mathrm{ab} \pm 9,1$ & $86,5 \mathrm{~b} \pm 8,7$ \\
GMD $(\mathrm{g})$ & $32,8 \pm 5,6$ & $31,5 \pm 4,0$ & $32,3 \pm 2,8$ \\
CA $(\mathrm{kg} / \mathrm{kg})$ & $3,19 \mathrm{a} \pm 4,4$ & $2,99 \mathrm{ab} \pm 2,9$ & $2,76 \mathrm{~b} \pm 2,1$ \\
\hline
\end{tabular}

Médias seguidas de letras diferentes, na mesma linha, diferem significativamente pelo teste de Tukey $(\mathrm{P}<0,05)$. Sendo $\mathrm{TA}=$ dieta sem inclusão de casca de soja; TACS = substituição de 50\% de alfafa por casca de soja; e TCS = substituição de $100 \%$ de alfafa por casca de soja. 
Tabela 3 - Parâmetros de carcaça e do trato gastrintestinal de coelhos abatidos aos 77 dias de idade.

\begin{tabular}{|c|c|c|c|}
\hline & TA & TACS & TCS \\
\hline Peso de carcaça $(\mathrm{g})$ & $1060,0 \pm 31,2$ & $1070,0 \pm 88,3$ & $1055,0 \pm 17,8$ \\
\hline Rendimento da carcaça $(\%)$ & $53,1 \pm 1,3$ & $53,6 \pm 2,1$ & $53,7 \pm 0,9$ \\
\hline Peso de fígado $(\mathrm{g})$ & $62,5 \pm 6,4$ & $51,2 \pm 4,7$ & $56,2 \pm 9,4$ \\
\hline Peso de pele $(\mathrm{g})$ & $238,2 \mathrm{a} \pm 13,1$ & $223,7 \mathrm{ab} \pm 12,5$ & $211,2 b \pm 7,5$ \\
\hline TGI repleto & $138,7 \pm 13,1$ & $\begin{array}{c}\text { gastrintestinais- } \\
150,0 \pm 14,1\end{array}$ & $142,5 \pm 16,6$ \\
\hline Estômago repleto & $91,2 \pm 13,1$ & $93,7 \pm 4,8$ & $105,0 \pm 13,5$ \\
\hline Ceco vazio & $35,0 \pm 7,0$ & $45,0 \pm 7,0$ & $43,7 \pm 10,3$ \\
\hline
\end{tabular}

Médias seguidas de letras diferentes, na mesma linha, diferem significativamente pelo teste de Tukey $(\mathrm{P}<0,05)$. Sendo TA $=$ dieta sem inclusão de casca de soja; TACS = substituição de $50 \%$ de alfafa por casca de soja; e TCS = substituição de $100 \%$ de alfafa por casca de soja.

ceco vazio entre os tratamentos. No entanto, GIDENNE (1996) comenta que, mantendo-se constante o nível de fibra dietética, pode ocorrer maior desenvolvimento de cecos com fontes de fibra mais digestíveis pela microflora intestinal, devido a estímulos químicos mais intensos, como o aumento na concentração de ácidos graxos voláteis oriundos da ação microbiana, além de efeito físico relacionado ao fluxo e refluxo entre ceco e cólon dos coelhos, caracterizando hipomotilidade responsiva à hiperfermentação pela microbiota cecal. Tal fato é confirmado pelo estudo desenvolvido por ARRUDA et al. (2003), que encontram maior peso de ceco e conteúdo cecal para animais alimentados com casca de soja, o que é justificado pela natureza química da parede celular desse ingrediente fibroso. Porém, no presente trabalho, a variabilidade individual entre os animais pode ter impedido a visualização desse resultado.

A tabela 4 demonstra o índice de viabilidade econômica proporcionado pelo uso da casca de soja em substituição total ao feno de alfafa. Esse ingrediente, além de baratear o custo da dieta, também melhorou a conversão alimentar, proporcionando um índice de eficiência bioalimentar (IEBA) 66,34\% melhor para os

Tabela 4 - Índice de eficiência bioalimentar (IEBA) de coelhos abatidos aos 77 dias de idade.

\begin{tabular}{lcc}
\hline Tratamentos & $\begin{array}{c}\text { Custo do kg da dieta* } \\
(\mathrm{R} \$)\end{array}$ & $\begin{array}{c}\text { IEBA } \\
(\mathrm{R} \$ \mathrm{~kg} \text { de PV })\end{array}$ \\
\hline TA & 0,66 & 2,10 \\
TACS & 0,57 & 1,70 \\
TCS & 0,50 & 1,38 \\
\hline
\end{tabular}

*Custo calculado em agosto de 2010. animais alimentados com casca de soja em comparação àqueles que receberam feno de alfafa como ingrediente volumoso da dieta.

\section{CONCLUSÃO}

A inclusão de casca de soja na alimentação de coelhos em crescimento mostra-se promissora, pois mantém índices satisfatórios de desempenho e rendimento de abate, aliados à melhor viabilidade econômica.

\section{COMITÊDE ÉTICA E BIOSSEGURANÇA}

Declaração nos documentos suplementares. Declaramos, para os devidos fins, que o trabalho "Uso de casca de soja em substituição ao feno de alfafa em rações para coelhos em crescimento" foi realizado no ano de 2009. Como fazia parte de um projeto guarda-chuva de produção animal, iniciado em 2007, não foi submetido à apreciação do Comitê de Ética e Bem Estar animal, pois, nesta época, esse tipo de projeto não necessitava de submissão ao referido Comitê. Ressaltamos que, no decorrer do experimento apresentado no artigo para avaliação, os animais não sofreram injúrias que comprometessem seu bem estar.

\section{REFERÊNCIAS}

AEC. Recomendações para nutrição. 5.ed. Antony, France: RHÔNE-POULENC, 1987. 86p.

ASSOCIATION OF OFFICIAL ANALYTICAL CHEMISTS AOAC. Official methods of analysis. 16.ed. Washington, D.C.: $1995.1094 p$.

ARRUDA, A.M.V. et al. Importância da fibra na nutrição de coelhos. Semina: Ciências Agrárias, v.24, n.1, p.181-190, 2003. Disponível em: <http://www.uel.br/revistas/uel/index.php/ semagrarias/article/view/2153/1847>. Acesso em: 10 jan. 2011. 
ARRUDA, A.M.V. et al. Desempenho e características de carcaça de coelhos alimentados com rações contendo diferentes níveis de amido e fontes de fibra. Revista Brasileira Zootecnia, v.32, n.6, p.1311-1320, 2003. Disponível em: <http:// www.scielo.br/scielo.php?script $=$ sci_arttext\&pid $=S 1516$ $35982003000600005>$. Acesso em: 10 jan. 2011.

COSTA, P.T.C. Avaliação econômica do frango de corte na fase final. In: CONFERENCIA APINCO DE CIENCIA E TECNOLOGIA AVICOLA, 1999, Campinas, SP. Anais... Campinas: FACTA, 1999. p.71-82.

FIGUEIRA, J.L. Casca de soja na alimentação de coelhos em crescimento em substituição aos fenos de alfafa e coastcross. 2009. 37f. Dissertação. (Mestrado em Zootecnia) - Curso de Pós-graduação em Zootecnia, Universidade Estadual de Maringá, PR.

GIDENNE, T. Nutritional and ontogenic factors affecting rabbitcaeco-colic digestive physiology. In: WORLD RABBIT CONGRESS, 6., 1996, Tolouse. Invited papers... Toulouse: AFC- INRA, 1996. p.13-28.

HERRERA, A.P.N. Eficiência produtiva e avaliação nutricional de dietas simplificadas a base de forragens para coelhos em crescimento. 2003. 104f. Tese (Doutorado em Ciência Animal) - Escola de Veterinária, Universidade Federal de Minas Gerais, MG.

KOLPFENSTEINT, T.; OWEN, F. Soybean hulls- an energy supplement for ruminants. Animal Health \&Nutrition, Abr. p.28-32, 1987.

LEBAS, F. et al. O coelho. Cría e patología. Roma: ONUFAO, 1986. 278p.

MEJIA, A.M.G. Estratégias para avaliação nutricional da polpa cítrica seca em suínos em terminação. 1999. $90 \mathrm{f}$.
Tese (Doutorado em Zootecnia)- Escola de Veterinária da Universidade Federal de Minas Gerais, MG.

NICODEMUS, N.et al. Effect of substitution of soybean hull and grape seed meal mixture for traditional fiber sources on digestion and performance of growing rabbits and lacting does. Journal of Animal Science, v.85, p.181-187, 2007. Disponível em: <http://www.animal-science.org/content/85/1/ 181.full>. Acesso em: 12 dez. 2011.

QUADROS A.R.B. et al. Avaliação nutricional da casca de soja integral ou moída, ensilada ou não, para suínos em fase de crescimento. Acta Scientiarum. Animal Sciences, v.29, n.1, p.31-38, 2007. Disponível em: <http://eduem.uem.br/ojs/ index.php/ActaSciAnimSci/article/view/249/156>. Acesso: 15 jan. 2012.

RETORE, M. et al. Efeito da fibra de co-produtos agroindustriais e sua avaliação nutricional para coelhos. Arquivos Brasileiros de Medicina Veterináriae Zootecnia, v.62, n.5, p.1232-1240, 2010. Disponível em: $<$ http://www.scielo.br/scielo.php?script=sci_arttext\&pid=S0102$09352010000500028 \& \operatorname{lng}=$ en\&nrm=iso>. Acesso em: 21 set. 2011.

SAS, Institute Incorporation. SAS Version 9.1. Cary, NC, 2003. 7857p.

SCAPINELLO, C. et al. Fenos de leucena (leucaenaleucocephala e leucaenaleucocephala cv. 'Cunningham') para coelhos em crescimento: digestibilidade e desempenho. Acta Scientiarum. Animal Science, v.25, n.2, p.301-306, 2003. Disponível em: <http://eduem.uem.br/ojs/index.php/ActaSciAnimSci/ article/view/2006/1405>. Acesso em: 18 jan. 2011.

SERRANA, NUTRIÇÃO ANIMAL. Casca de soja na alimentação de ruminantes. Fev. de 2006. Disponível em: <http://www.serrana.com.br/nutricaoanimal/boletimtecnico/ PDF/Fevereiro2006.pdf>. Acesso em: 23 fev. 2010. 